\title{
Male erectile dysfunction following spinal cord injury: a systematic review
}

\author{
D DeForge*,1, J Blackmer ${ }^{1}$, C Garritty ${ }^{2}$, F Yazdi ${ }^{2}$, V Cronin $^{1}$, N Barrowman ${ }^{2,3}$, M Fang $^{2}$, V Mamaladze ${ }^{2}$, \\ L Zhang ${ }^{4}, \mathrm{M} \mathrm{Sampson}^{2}$ and D Moher ${ }^{2,3}$ \\ ${ }^{1}$ The Rehabilitation Centre, Ottawa Hospital, Ottawa, Ontario, Canada; ${ }^{2}$ Children's Hospital of Eastern Ontario \\ Research Institute, Ottawa, Ontario, Canada; ${ }^{3}$ Department of Pediatrics, Faculty of Medicine, University of Ottawa, \\ Ottawa, Ontario, Canada; ${ }^{4}$ University of Saskatchewan, Saskatoon, Ontario, Canada
}

\begin{abstract}
Study design: Systematic review.
Objective: To review sexuality in persons with spinal cord injuries (SCIs), and to report the effectiveness of erectile interventions.

Methods: Reports from six databases (1966-2003), selected annual proceedings (1997-2002) and manufacturer's information were screened against eligibility criteria. Included reports were abstracted and data pooled from case-series reports regarding intracavernous injections and sildenafil.
\end{abstract}

Results: From 2127 unique reports evaluated, 49 were included. Male sexual dysfunction was addressed in these reports of several interventions (behavioural therapy, topical agents, intraurethral alprosatadil, intracavernous injections, vacuum tumescence devices, penile implants, sacral stimulators and oral medication). Penile injections resulted in successful erectile function in 90\% (95\% CI: 83\%, 97\%) of men. Sildenafil resulted in 79\% (95\% CI: 68\%, $90 \%$ ) success; the difference in efficacy was not statistically significant. Five case-series reports involving 363 participants with penile implants demonstrated a high satisfaction rate, but a $10 \%$ complication rate.

Conclusions: A large body of evidence addressing sexuality in males focuses on erection. Penile injection, sildenafil and vacuum devices generally obviate the need for penile implants to address erectile dysfunction. Interventions may positively affect sexual activity in the short term. Longterm sexual adjustment and holistic approaches beyond erections remain to be studied. Rigorous study design and reporting, using common outcome measures, will facilitate higher quality research. This will positively impact patient care.

Sponsorship: Agency for Healthcare Research and Quality, US Department of Health and Human Services, 2101 East Jefferson Street, Rockville, MD 20852, USA.

Spinal Cord (2006) 44, 465-473. doi:10.1038/sj.sc.3101880; published online 29 November 2005

Keywords: spinal cord injury; male sexuality; male sexual function; research quality; systematic review

\section{Introduction}

Health care providers are increasingly aware of the importance of sexuality in the process of rehabilitation after a spinal cord injury (SCI) and identify it as a high priority to improve quality of life for persons with

*Correspondence: D Deforge, Division of Physical Medicine \& Rehabilitation, University of Ottawa, The Ottawa Hospital General Campus, 505 Smyth Road, Ottawa, Ontario, Canada K1H 8M2

Note: Sexuality and Reproductive Health Following Spinal Cord Injury. Evidence Report (AHRQ Publication No. 05-E003-2). The views expressed in this article are those of the authors and do not necessarily reflect those of the Agency for Healthcare Research and Quality or the US Department of Health and Human Services. Appendices and Evidence tables cited in this report are available at http://www.ahrq. gov/downloads/pub/evidence/pdf/sexlspine/sexlspine.pdf
SCIs. ${ }^{1,2}$ The impact of an SCI on sexual function depends on the severity and location of the injury. 3,4 Following an SCI, both men and women report decreased desire, and lower frequency of sexual activity. ${ }^{5}$ Moreover, psychological elements (eg, body image, self-esteem and aspirations) and social elements (gender, age and culture) all mould the sexual identity of a person with an SCI. ${ }^{6}$

The Agency for Healthcare Research and Quality and a federal partner, The Consortium for Spinal Cord Medicine, commissioned the University of Ottawa's Evidence-based Practice Center to conduct a feasibility study to determine if there was sufficient credible literature for a comprehensive systematic review on the 
topic of 'Sexuality and Reproductive Health Following SCI'. The research team found sufficient literature to address the following questions pertaining to sexuality:

- Is sildenafil really more benign than intracavernous injections?

- How does the morbidity of prostaglandin injections compare with the older, less-expensive papaverine or phentolamine?

- What is the morbidity of vacuum tumescence devices?

- What indications, if any, remain for implantable penile prosthetic devices?

\section{Methods}

\section{Search strategy}

Building on the preliminary search conducted for the feasibility report, an updated search was conducted on Medline (1966-June Week 1 2003), Premedline (13 June 2003), CINAHL (1975-June Week 1 2003), Cochrane Central Register of Controlled Trials (1st Quarter, 2003), SocioFile (1974-June 2003) and PsycInfo (1887June Week 1 2003) and is reported elsewhere (http:// www.ahrq.gov/clinic/epcindex.htm). Reference lists in relevant documents were not searched.

Additional published literature was sought through searches of relevant associations' proceedings for the years 1997-2002, and industry was contacted for ongoing and/or unpublished data.

\section{Eligibility criteria}

Published and unpublished studies, of any research design or language of publication, that enrolled male, adult and/or adolescent populations with SCI, were considered for inclusion. Interventions included devices (eg penile rings, vibrators and vacuum devices), prescription medications (oral, creams, intracavernous injections, subcutaneous injections or intrameatal MUSE), surgery (penile implants or spinal cord stimulators), hormones or involved cognitive/behavioural aspects (eg masturbation). Single case reports and opinion articles were excluded, as were studies reporting on congenital abnormalities.

\section{Study selection}

Relevance screening, assessments of study quality and data abstraction were completed electronically. Reports were not masked for authorship and/or affiliations, given the equivocal evidence regarding the benefits of this practice. 7,8

Calibration exercises preceded each step of the screening process. As an extension of the feasibility study where screening was directed at bibliographic records (ie, title, authors, key words, abstracts), full articles were screened by two team pairings (DD and VC; JB and NL). Records were included that appeared to contain pertinent study information when there was no unequivocal reason for exclusion. Disagreements were resolved by consensus and, if necessary, by third party resolution. Excluded studies and reasons for exclusion are available elsewhere (http://www.ahrq. gov/clinic/epcindex.htm).

\section{Data abstraction}

Data compiled from each report included the study design (eg randomised controlled trial (RCT), cohort study), study quality, participants (eg gender, diagnoses, control group characteristics), intervention/exposure, outcome measures (eg erection, satisfaction) and study results and conclusions.

The contents of each included study were independently abstracted by two of four team members (FY, VC, VM, JM). Reviewers undertook an initial 'calibration' exercise with two studies, and checked all data abstracted by their counterpart.

\section{Study quality}

Study quality was assessed independently by two assessors.

RCTs were assessed using the Jadad scale. This validated scale rates reporting of the generation of random assignments and double blinding, and descriptions of dropouts and withdrawals from each group. ${ }^{9}$ The scoring ranges from zero to five, with higher scores indicating higher quality. In addition, allocation concealment (keeping randomisation blind until participants are assigned to an intervention group) was assessed as adequate, inadequate or unclear. ${ }^{10}$

The Newcastle-Ottawa scale (NOS) was used to rate cohort and case-control study reports according to the selection of the study groups, the comparability of the groups and the determination of either the exposure for case-control studies, or the outcome of interest for cohort studies. $^{11}$

Quality assessments of noncomparative case-series reports were assessed using a 19-item instrument adapted from the journal Opthalmology. ${ }^{12}$

No quality assessments were completed on observational studies.

\section{Data synthesis}

Qualitative syntheses of abstracted data were completed on a question-specific basis, with studies grouped according to research design (eg, RCTs, observational studies). Tabulated information not presented here is available elsewhere (http://www.ahrq.gov/clinic/epcindex. htm).

Where quantitative data synthesis was deemed appropriate, forest plots were constructed using Wilson score confidence intervals around individual study proportions. ${ }^{13}$ Pooled estimates and their confidence intervals were obtained using the random effects estimator of Laird and Mosteller. ${ }^{14}$ 


\section{Results}

Data record identification, assessment and exclusion are summarised in Figure 1. Of 2127 reports evaluated against the eligibility criteria, 1627 were excluded after the initial screening for relevance. The remaining 288 reports were then retrieved, and after a more detailed

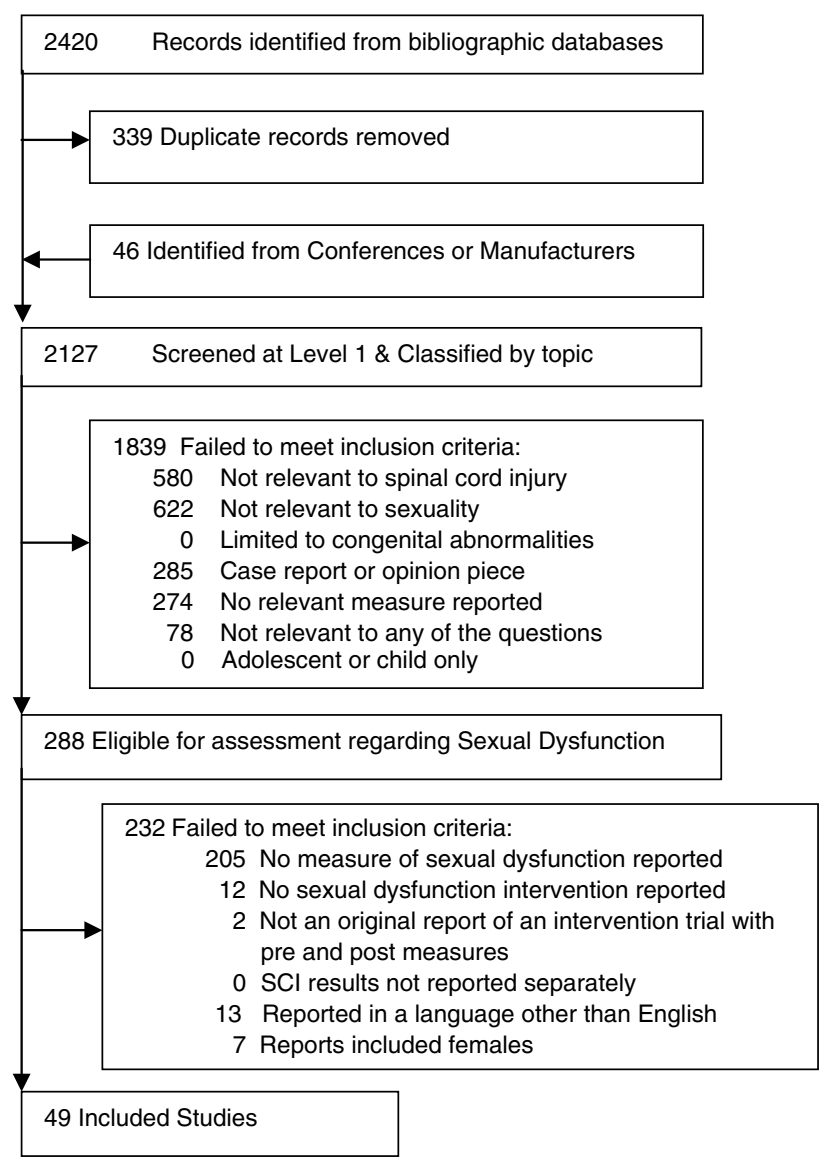

Figure 1 QUOROM flow chart relevance assessment, 187 failed to meet the inclusion criteria. All 49 reports included in this systematic review examined sexual function in males with SCI. As we have already mentioned, this paper focuses on the results of the male intervention studies only.

\section{Exclusions}

The majority of articles regarding male sexual dysfunction after SCI were excluded as opinion pieces or review articles, and many reports were also excluded for not reporting preintervention erectile function.

\section{Behavioural interventions}

One case-series study examined behavioural interventions. Courtois et al. ${ }^{15}$ demonstrated improvement in penile rigidity in 10 SCI males after biofeedback followed by home perineal muscle training exercises. No measurements of sexual satisfaction were incorporated into the study. The study quality score was $11 / 19$.

\section{Topical and intraurethral agents}

An attractive alternative to systemic or injected medication is the use of a vasoactive agent absorbed into the penis to stimulate erection (Table 1). Exterior topical agents were examined in three noncomparative caseseries studies ${ }^{16-18}$ and one placebo-controlled clinical trial. ${ }^{19}$ Two case-series studies evaluated intraurethral Alprostadil (prostaglandin). ${ }^{20-22}$ Topical and intraurethral pharmaceutical agents are effective about a quarter of the time in treating individuals with SCI erectile dysfunction. Although initially thought to be a hopeful technique, intraurethral treatment has not been useful for most of the male SCI population.

\section{Intracavernous (penile) injections}

Intracavernous (penile) injections of vasoactive substances to treat SCI male impotence have been reported

Table 1 Evidence regarding transcutaneous vasoactive agents to stimulate erection in men with SCI

\begin{tabular}{|c|c|c|c|c|}
\hline Author (year) & Intervention & Response & $\begin{array}{l}\text { Harms (number of } \\
\text { patients) }\end{array}$ & Study quality \\
\hline Beretta et al $(1993)^{16}$ & $\begin{array}{l}\text { Transcutaneous } \\
\text { minoxidil }\end{array}$ & $4 / 15$ full erections & Headache (1) & $8 / 19$ \\
\hline $\begin{array}{l}\text { Kim and McVary } \\
(1995)^{17}\end{array}$ & Topical prostaglandin & $2 / 9$ clinical erections & Not reported & $10 / 19$ \\
\hline Kim et al $(1995)^{19}$ & Topical papaverine gel & $3 / 12$ full erections & Not reported & Not applicable (non-RCT) \\
\hline $\begin{array}{l}\text { Sonsken and Biering- } \\
\text { Sorenson }(1992)^{18}\end{array}$ & Nitroglycerine patch & $5 / 17$ full erections & Headache (6) & $7 / 19$ \\
\hline Bodner et al (1999) ${ }^{21}$ & $\begin{array}{l}\text { Intraurethral } \\
\text { alprosatadil }\end{array}$ & $\begin{array}{l}7 / 17 \text { partial erection } \\
3 / 15 \text { erections } \\
\text { sufficient for } \\
\text { intercourse }\end{array}$ & $\begin{array}{l}\text { Penile ring necessary } \\
\text { to prevent systemic } \\
\text { hypotension }\end{array}$ & $8 / 19$ \\
\hline $\begin{array}{l}\text { Waldbaum et al } \\
(1998)^{22}\end{array}$ & $\begin{array}{l}\text { Intraurethral } \\
\text { alprosatadil }\end{array}$ & $\begin{array}{l}4 / 15 \text { achieved } \\
\text { erections sufficient for } \\
\text { intercourse }\end{array}$ & $\begin{array}{l}\text { Penile ring necessary } \\
\text { to prevent systemic } \\
\text { hypotension }\end{array}$ & Not applicable (abstract) \\
\hline
\end{tabular}


for several decades. Injected substances include papaverine, phentolamine, prostaglandin E1 or combinations of two or three of the above. Many clinics use

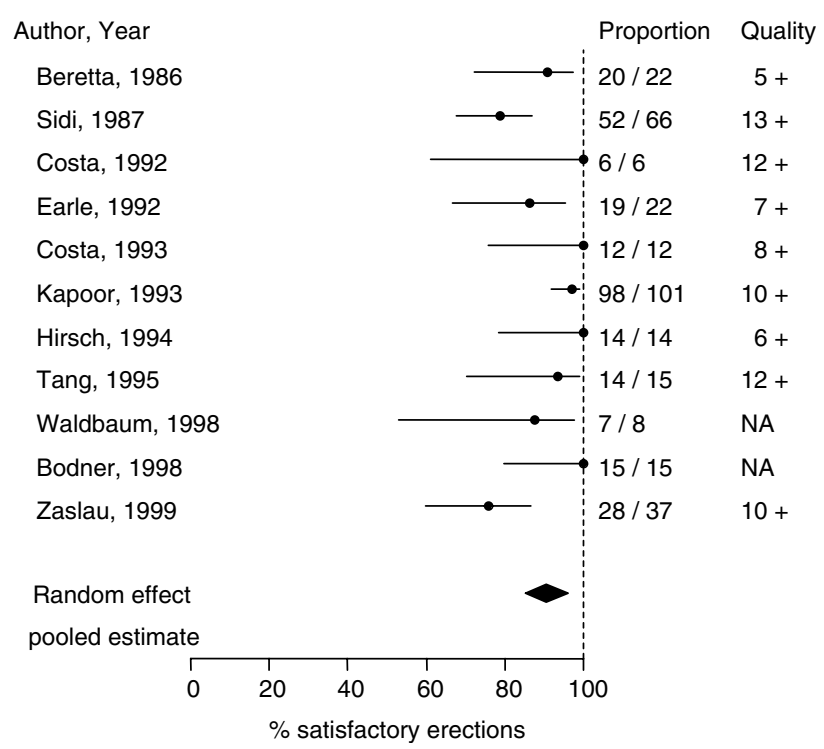

Figure 2 Meta-analysis of intracavernous injections caseseries reports. Forest plot of the success rate of intracavernous injections in noncomparative case-series studies that reported satisfactory erections as an outcome. The data were pooled and the overall estimate and its confidence interval were calculated using the random effects estimator of Laird and Mosteller. ${ }^{14}$ Quality scores are out of a possible 19. NA $=$ not assessed. $+/-$, allocation concealment reported/not reported combination therapy (papaverine, phentolamine, prostaglandin E1) for economic reasons, and there is no clear difference in efficacy between these substances. Data of 'satisfactory erection' as a common outcome measure was pooled from eight noncomparative case-series studies in the US, Australia, Italy, India, China and France (Figure 2). ${ }^{23-30}$ Overall, these interventions resulted in a random effects pooled estimate of $90 \%$ satisfactory erection response rate (95\% CI 83\%, 97\%).

Six noncomparative case-series studies ${ }^{25,26,28-31}$ and one $\mathrm{RCT}^{32}$ of 263 patients in the USA, Australia, Italy, India, China and France reported side effects (Table 2).

Zaslau et $a l^{28}$ and Sidi $e t a l^{29}$ found that injections were less effective in individuals with hypertension or diabetes along with SCI.

In a comparative case series, Chancellor et $a l^{33}$ compared vacuum-pump devices with papaverine injections in 18 males with SCI. The injections and pumps were equally effective and neither group suffered any complications during the study. After trying both, seven patients chose to remain with the pump and another seven chose the injections. In a third arm of this study, no patients achieved satisfactory results with topical minoxidil. Study quality was $8 / 19$.

\section{Vacuum tumescence devices}

Zasler and $\mathrm{Katz}^{34}$ studied a novel vacuum-pump system (Synergist) with a silicon sheath, in a case series of 20 males with SCI. Patient and partner assessments of the

Table 2 Side effects associated with intracavernous injections

\begin{tabular}{|c|c|c|c|c|}
\hline Author (year) & $\begin{array}{l}\text { Number of } \\
\text { patients } \\
\text { treated }\end{array}$ & Substance & Side effects (number of patients) & Study quality \\
\hline Beretta et al $(1986)^{31}$ & 22 & Papaverine & Priapism (7) & $5 / 19$ \\
\hline Earle et al $(1992)^{27}$ & 22 & $\begin{array}{l}\text { Papaverine, papaverine and } \\
\text { phentolamine, } \\
\text { prostaglandin E1 }\end{array}$ & Not reported & $7 / 19$ \\
\hline Hirsch et al $(1994)^{25}$ & 27 & Prostaglandin E1 & $\begin{array}{l}\text { Penile scarring detectable only on } \\
\text { ultrasound after repeated use ( } 2)\end{array}$ & $6 / 19$ \\
\hline Kapoor et al $(1993)^{30}$ & 101 & Papaverine & $\begin{array}{l}\text { Subcutaneous haematoma ( } 3) \text {; } \\
\text { cavernosa fibrosis after } 3 \text { years use } \\
\text { (2); Priapism (1); vasovagal reaction } \\
\text { requiring dosage reduction (1) }\end{array}$ & $10 / 19$ \\
\hline $\begin{array}{l}\text { Renganathan et al } \\
(1997)^{32}\end{array}$ & 28 & Papaverine & $\begin{array}{l}\text { Priapism (1); local swelling requiring } \\
\text { no intervention }(8)\end{array}$ & $\begin{array}{l}0 / 5 \text { Jadad } \\
\text { Crossover study } \\
\text { No concealment }\end{array}$ \\
\hline Sidi et al $(1987)^{29}$ & 66 & $\begin{array}{l}\text { Papaverine or papaverine/ } \\
\text { phentolamine mixture }\end{array}$ & $\begin{array}{l}\text { Priapism (4); minor haematomas (3); } \\
\text { localized site induration, requiring } \\
\text { discontinuation (1) }\end{array}$ & $13 / 19$ \\
\hline Tang et al $(1995)^{26}$ & 15 & Prostaglandin E1 & Pain at injection site (2) & $12 / 19$ \\
\hline Zaslau et al (1999) ${ }^{28}$ & 28 & $\begin{array}{l}\text { Papaverine and } \\
\text { prostaglandin E1 mixture }\end{array}$ & Pain at injection site (2) & $10 / 19$ \\
\hline
\end{tabular}


Table 3 RCT evidence for the use of sildenafil for sexual dysfunction in men with SCI

\begin{tabular}{|c|c|c|c|c|}
\hline Author (year) & $\begin{array}{l}\text { Number of } \\
\text { subjects ( } \mathrm{N}) \text {; } \\
\text { number of } \\
\text { dropouts (D) }\end{array}$ & Results & Adverse events & Study quality \\
\hline $\begin{array}{l}\text { Giuliano et al } \\
(1999)^{40}\end{array}$ & $N=178 ; D=7$ & $\begin{array}{l}76 \% \text { improved erections and a } \\
\text { preference for sildenafil versus } 4 \% \\
\text { for placebo }\end{array}$ & $\begin{array}{l}\text { Headache: } \text { sildenafil }=30, \\
\text { placebo }=8 \\
\text { Flushing: sildenafil }=12 \text {, placebo }=2 \\
\text { Dyspepsia: } \text { sildenafil }=5 \text {, placebo }=0 \\
\text { Visual effects: } \text { sildenafil }=4, \\
\text { placebo }=0 \\
\text { Rhinitis: } \text { sildenafil }=3 \text {, placebo }=0\end{array}$ & $\begin{array}{l}3 / 5 \text { Jadad } \\
\text { Cross-over } \\
\text { design } \\
\text { adequate } \\
\text { concealment }\end{array}$ \\
\hline $\begin{array}{l}\text { Maytom et al } \\
(1999)^{41}\end{array}$ & $N=27 ; D=0$ & $\begin{array}{l}\text { Erections in clinic }>60 \% \text { at base: } \\
\text { sildenafil }=65 \% \text {; placebo }=8 \% \\
\text { Global Efficacy Question (did } \\
\text { treatment improve erections?): } \\
\text { sildenafil }=75 \% \text {; placebo }=7 \%\end{array}$ & $\begin{array}{l}\text { Headache: } \text { sildenafil }=4 \text {, placebo }=1 \\
\text { Dyspepsia: } \text { sildenafil }=1, \text { placebo }=0 \\
\text { Vomiting: sildenafil }=1 \text {, placebo }=0 \\
\text { Dizziness: sildenafil }=1 \text {, placebo }=0 \\
\text { Rash: } \text { sildenafil }=2, \text { placebo }=3\end{array}$ & $\begin{array}{l}3 / 5 \text { Jadad } \\
\text { cross-over } \\
\text { design } \\
\text { concealment } \\
\text { unclear }\end{array}$ \\
\hline
\end{tabular}

device efficacy and sex-life satisfaction were very good to excellent and no harms were reported. The report quality assessment score was $13 / 19$.

Heller et $a l^{35}$ studied vacuum-pump systems in 30 males with SCI. Participants were trained in the clinic, and 17 opted to purchase the device and use it at home. Some participants experienced transient testicle swelling $(n=3)$ or transient petechial haemorrhages $(n=5)$ that resolved within $1 \mathrm{~h}$. The report quality assessment score was $8 / 19$.

\section{Sildafenil-RCTs}

Nine reports of RCTs of sildafenil in SCI males ${ }^{36-44}$ covered two separate trials, ${ }^{40,41}$ involving 205 participants from the UK, France and Australia (Table 3). Different trial designs (crossover and parallel) and outcome measures precluded statistical pooling.

\section{Sildafenil-case series}

Many of the case-series studies used noncomparable outcome measures. However, seven studies between 1999 and 2001 in the USA, Germany, Spain, Switzerland and Japan reported the subjects' assessments of erectile function for sexual intercourse at home. ${ }^{45-51}$ Overall, sildenafil resulted in a random effects pooled estimate of $79 \%$ successful erectile function $(95 \% \mathrm{CI}$ : $68 \%, 90 \%$ ) (Figure 3). The broad confidence interval reflects substantial heterogeneity in the subjective, second-hand, personal experience outcome measures. No standardised questionnaire was used across studies. Both of these studies received a quality rating of $3 / 5$ on the Jadad scale.

Although other phosphodiesterase inhibitors have come into the market since Viagra ${ }^{\circledR}$, no SCI treatment data for these drugs was available at the time of this review.

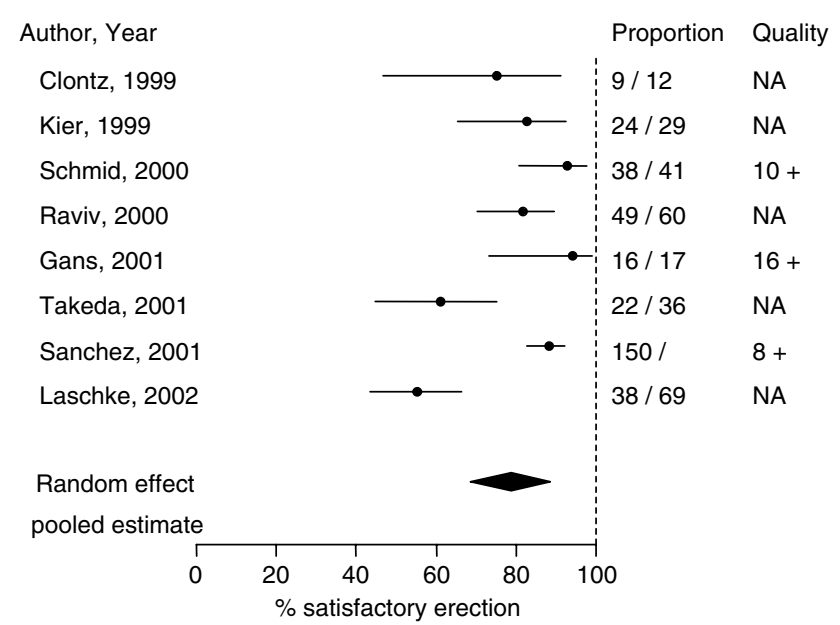

Figure 3 Meta-analysis of sildenafil citrate case-series reports. Forest plot of the use of sildenafil in noncomparative caseseries studies that reported erectile function for intercourse as an outcome. The data were pooled and the overall estimate and its confidence interval were calculated using the random effects estimator of Laird and Mosteller. ${ }^{14}$ Quality scores are out of a maximum of 19 . NA $=$ not assessed. $+/-$, allocation concealment reported/not reported

\section{Penile implants}

Penile implants have been used in SCI males for decades, although with decreasing frequency. While this topic was frequently discussed in the papers reviewed, only five case-series studies examined penile implants for either erectile dysfunction or erectile dysfunction plus urinary incontinence (Table 4). ${ }^{52-56}$ These studies involved 363 SCI males in the US, Germany and Japan, using a variety of prostheses including inflatable, semirigid, semiflexible and flexible devices.

Penile implants are very satisfactory for those who do not have complications, but the serious complication 
Table 4 Side effects associated with the use of sildenafil for sexual dysfunction in men with SCI

\begin{tabular}{|c|c|c|c|}
\hline Author (year) & $\begin{array}{l}\text { Intervention } \\
\text { (number of } \\
\text { patients) }\end{array}$ & Side effects (number of patients) & Study quality \\
\hline Anonymous $(1999)^{37}$ & Sildenafil (26) & Dyspepsia (2); respiratory disorder (2) & Not assessed \\
\hline Clontz et al (abstract, 1999) ${ }^{36}$ & Sildenafil (12) & Visual changes (1); headache (3) & Not assessed \\
\hline Derry et al $(1998)^{38}$ & $\begin{array}{l}\text { Sildenafil } \\
(27)+\text { vibration }\end{array}$ & Headache (4); dyspepsia (1); dizziness (1); anxiety (1) & $\begin{array}{l}3 / 5 \text { Jadad } \\
\text { concealment not } \\
\text { reported }\end{array}$ \\
\hline Giuliano et al (1999) ${ }^{40}$ & Sildenafil (178) & $\begin{array}{l}\text { Headache (30); flushing (12); dyspepsia (5); rhinitis } \\
\text { (3); abnormal vision (4); discontinued treatment (6) }\end{array}$ & $\begin{array}{l}2 / 5 \text { Jadad } \\
\text { concealment unclear }\end{array}$ \\
\hline Kier et al (1999) ${ }^{46}$ & Sildenafil (29) & $\begin{array}{l}\text { Visual change (1); headache (5); dizziness (1); } \\
\text { flushing (1) }\end{array}$ & Not assessed \\
\hline Laschke et al (abstract, 2002) ${ }^{50}$ & Sildenafil (69) & Headaches and flushing (17); visual change (7) & Not assessed \\
\hline Sanchez et al $(2001)^{51}$ & Sildenafil (170) & $\begin{array}{l}\text { Headache (10); flushing (15); GI discomfort (7); nasal } \\
\text { congestion (8); visual disturbances ( } 7) \text {; restlessness, } \\
\text { palpitations, hiccup, dry mouth (9); unbearable } \\
\text { abdominal pain (1) }\end{array}$ & $8 / 19$ \\
\hline Schmid et al $(2000)^{48}$ & Sildenafil (41) & $\begin{array}{l}\text { Headache (3); dizziness (2); flushing (2); dyspepsia } \\
\text { (1); blurred vision (1); withdrew due to adverse events } \\
\text { (2) }\end{array}$ & $10 / 19$ \\
\hline Shenot et al (abstract, 1999) ${ }^{39}$ & Sildenafil (29) & Headache (2); flushing (2) & Not assessed \\
\hline Takeda et al (abstract, 2000) ${ }^{47}$ & Sildenafil (36) & Headache, facial flush, chest 'strangled feeling' (6) & Not assessed \\
\hline
\end{tabular}

rate was consistently close to $10 \%$. Furthermore, patients who have an implant removed are likely to have damage to the penile tissues that would make them nonresponsive to intracavernous injections or vacuum devices.

\section{Sacral stimulation}

Sacral stimulators have been championed as a method of achieving bladder and bowel continence in patients with complete SCI. In general, the procedure is reserved for complete injuries since it necessitates a sacral rhizotomy with loss of a reflex erection, voiding or defecation. van der Aa et $a l^{57,58}$ reported that 29 of 33 subjects with implants could achieve a full sustainable erection by stimulating the $\mathrm{S} 2$ or $\mathrm{S} 3$ anterior routes. It was not reported how the stimulator-induced erection impacted sexual function, or if there were side effects such as bladder or bowel incontinence during sexual activity. The quality score was 5/19.

\section{Discussion and conclusions}

The long list of excluded studies and reasons for exclusion speaks to the need for adherence to rigorous standards for trial design, conduct and reporting, so that information may be pooled in a meaningful way. Many excluded reports were summaries of previously published work, sometimes with new case-series data added, but with incomplete information on the source of the data. Also, data on different aspects of one trial on a single group of patients was published multiple times in different journals with the author list rearranged, causing an inflated impression of the numbers of studies and patients involved.

Researchers should learn from the plethora of sildenafil RCTs, given the variety of trial designs and outcome measures such that data could not be pooled in a systematic review. As new pharmaceutical agents are developed, they should be readily compared with sildenafil and with older techniques. For example, some authors used a validated erectile grading system such as Schramek's, whereas others used their own grading system; some authors used all or parts of the International Index of Erectile Function sexual satisfaction rating scale, whereas others designed their own scales. Common validated scales already exist and should be used for outcome measures, such as an erectile grading scale, an erectile satisfaction questionnaire and a quality of life measure. Strong medical evidence is built when 
large numbers of patients are treated and assessed in comparable ways.

An RCT is the gold standard for many interventions used in healthcare and several sildafenil RCTs were reported in this review. Participants may be less likely to agree to randomisation for an erectile function trial injecting unknown substances into their penises, and it may not be feasible or ethical to randomise men to undergo disfiguring surgery or neurosurgery for sexual dysfunction. Additionally, penile and sacral implants serve other functions as well as enhancing sexuality. Hence, most data for treatment intervention that included a control group was presented as case series.

Unfortunately, many case-series reports were excluded for lack of preintervention assessments. In the future, relatively easy improvements to study design as well as reporting of complete methodology, including how missing data was dealt with, dropouts, follow-up efforts and side effects, ${ }^{59,60}$ could improve the standard of evidence.

Most of the studies included in this systematic review were noncomparative case series. Mitigation of heterogeneity is not possible in studies without a well-matched control group, and requires judicious selection of comparable studies for a meta-analysis of single proportions (eg only more recent studies were pooled in this review). Random effects techniques for pooling results attempt to adjust for statistical heterogeneity, but consequently provide weaker inferences and do not obviate the need to carefully consider sources of heterogeneity. Broad confidence intervals from pooled data may obscure significant differences in treatment modalities, such as a possible but indiscernible difference between intercavernous injections and sildenafil.

\section{Specific questions}

How has the availability of Viagra ${ }^{\circledR}$ and other remediation affected sexual dysfunction and adjustment after SCI?

By far, the majority of articles regarding sexual dysfunction after SCI are either opinion pieces or review articles (Appendix $\mathrm{C}$; list of excluded studies). The only RCTs that were identified examined Viagra ${ }^{\circledR}$ for the treatment of erectile dysfunction. However, multiple case-series studies that had similar outcome measures were identified, thus allowing their data to be pooled.

\section{Is sildenafil really more benign than intracavernous injections?}

The erectile function pooled data for intracavernous injections (Figure 2) and sildenafil (Figure 3) were not significantly different $(P=0.1)$, despite the apparent magnitude of differences in comparable response $(90$ versus $79 \%$ ). Clinicians are aware that lower motor neuron-injured patients tend not to respond to sildafenil but do respond to injections. Side effects are summarised in Tables 2 and 5. Although the side effect profile is different (eg headache versus injection site pain), the frequency and seriousness of side effects are similar. The most serious side effect of injections was priapism (prolonged erection), which can be avoided by adjusting dosage in the clinic.

All of the sildenafil studies excluded patients on nitrate medications and there were no reported sudden deaths. Intracavernous injections are an option for patients on nitrate medications.

If subjects are reliable and have little sensation, the choice can be based on subject and partner preference.

\section{How does the morbidity of prostaglandin injections compare with the older, less-expensive papaverine or phentolamine?}

Papaverine, phentolamine and prostaglandin E1 are used alone, or for economic reasons in combination therapy, but there is no clear difference in efficacy between these substances. Prostaglandin E1 is less stable at room temperature and much more expensive than papaverine or phentolamine. Proponents cite a shorter half-life (decreased chance of priapism) and less injection-site pain and scarring as reasons to use this substance despite the expense.

Table 5 Case-series evidence for the use of penile implants for erectile dysfunction in men with SCI

\begin{tabular}{lcll}
\hline Author (year) & $\begin{array}{c}\text { Number of } \\
\text { implants }\end{array}$ & Complications (number of patients) \\
\hline Golji $(1979)^{52}$ & 30 & Infection causing extrusion (2); wound infections treated conservatively (2) & $\begin{array}{c}\text { Quality } \\
\text { score }\end{array}$ \\
Green and Sloan (1986) & 40 & Extruded rods (3); penile erosion (1); paraphimosis requiring circumcision (1) & $7 / 19$ \\
Gross et al (1996) & 209 & Problems requiring removal of implant (14); rod perforation (21) \\
Iwatsubo et al (1986) & 37 & Infection causing extrusion (2); severe pain (1); mechanical failure (1) \\
Montague (1994) & 47 & $\begin{array}{l}\text { Infection requiring removal (2); penile erosion requiring removal (1); } \\
\text { mechanical failure (2) }\end{array}$ \\
\hline
\end{tabular}


What is the morbidity of vacuum tumescence devices? When used with proper clinic instruction and according to the specifications of the manufacturers, vacuum tumescence devices have a very low morbidity rate with no irreversible effects noted. Isolated case reports of penile ischaemia should serve as a warning not to leave the device on too long and possibly to avoid its use in patients on anticoagulants, but cannot inform as to complication rate.

\section{What indications, if any, remain for implantable penile} prosthetic devices?

Implants could be used in patients who failed to respond to oral or injectable medications and vacuum devices, or who find these alternatives unacceptable, but most patients will respond to less invasive techniques. Implants are, however, useful to assist application of condom drainage systems.

\section{Future directions}

To date, the SCI male literature is relatively unidimensional, focusing on erection, with only one report of alternative treatment options. ${ }^{15}$ For example, efferent pathways have not been explored per se in men as they have been in women. The danger is that the clinician, faced with a suffering patient, simply reaches into their drawer for the drug sample.

Clinicians are also confronted with issues from same sex couples, with absolutely no literature to guide them. Well-conducted qualitative research would provide a great deal of clarity in these matters.

With evolving therapies, it is imperative that trials with negative results be thoroughly reported. If researchers do not report what 'did not work', systematic reviews will be skewed, creating unrealistic expectations for treatment modalities and even causing doctors to use less than optimum treatments.

\section{Acknowledgements}

This document was prepared by the University of Ottawa Evidence-based Practice Center, Ottawa, Canada. We gratefully acknowledge the following individuals who served on our Technical Expert Panel (acknowledgment does not reflect endorsement of this report): Drs David Chen, Stanley Ducharme, Stacy Elliott, Arthur Leader, Todd Linsenmeyer and Shawn Marshall. We also thank Dr Meg Sears who helped in the drafting and editing of this manuscript.

\section{References}

1 Fisher TL et al. Sexual health after spinal cord injury: a longitudinal study. Arch Phys Med Rehabil 2002; 83: 1043-1051.

2 Pervin-Dixon L. Sexuality and the spinal cord injured. J Psychosoc Nurs Ment Health Serv 1988; 26: 31-34.

3 Sipski ML, Alexander CJ, Rosen R. Sexual arousal and orgasm in women: effects of spinal cord injury. Ann Neurol 2001; 49: 35-44.
4 Biering-Sorensen F, Sonksen J. Sexual function in spinal cord lesioned men. Spinal Cord 2001; 39: 455-470.

5 Alexander CJ, Sipski ML, Findley TW. Sexual activities, desire, and satisfaction in males pre- and post-spinal cord injury. Arch Sex Behav 1993; 22: 217-228.

6 Sipski ML, Alexander CJ. Sexual activities, response and satisfaction in women pre- and post-spinal cord injury. Arch Phys Med Rehabil 1993; 74: 1025-1029.

7 Moher D et al. Does quality of reports of randomised trials affect estimates of intervention efficacy reported in metaanalyses? Lancet 1998; 352: 609-613.

8 Berlin JA. Does blinding of readers affect the results of meta-analyses? University of Pennsylvania Meta-analysis Blinding Study Group. Lancet 1997; 350: 185-186.

9 Jadad AR et al. Assessing the quality of reports of randomized clinical trials: is blinding necessary? Control Clin Trials 1996; 17: 1-12.

10 Schulz KF et al. Empirical evidence of bias. Dimensions of methodological quality associated with estimates of treatment effects in controlled trials. JAMA 1995; 273: 408-412.

11 Wells GA et al. The Newcastle-Ottawa Scale (NOS) for assessing the quality of nonrandomised studies in metaanalyses. 3rd Symposium on Systematic Reviews: Beyond the Basics, July 2000, Oxford. 2000.

12 Ophthalmology Study Design Worksheet \#3. Noncomparative (nonrandomized, noncontrolled) Interventional Case Series, 2004.

13 Newcombe RG. Improved confidence intervals for the difference between binomial proportions based on paired data. Stat Med 1998; 17: 2635-2650.

14 Laird NM, Mosteller F. Some statistical methods for combining experimental results. Int $J$ Technol Assess Health Care 1990; 6: 5-30.

15 Courtois F, Mathieu C, Charvier K. Sexual rehabilitation for men with spinal cord injury: preliminary report on a behavioral strategy. Sex Disabil 2001; 19: 153-157.

16 Beretta $\mathrm{G}$ et al. Transcutaneous minoxidil in the treatment of erectile dysfunctions in spinal cord injured men. Acta Eur Fertil 1993; 24: 27-30.

17 Kim ED, McVary KT. Topical prostaglandin-E1 for the treatment of erectile dysfunction [see comments]. J Urol 1995; 153: 1828-1830.

18 Sonksen J, Biering-Sorensen F. Transcutaneous nitroglycerin in the treatment of erectile dysfunction in spinal cord injured. Paraplegia 1992; 30: 554-557.

19 Kim ED, el Rashidy R, McVary KT. Papaverine topical gel for treatment of erectile dysfunction. J Urol 1995; 153: 361-365.

20 Bodner DR, Seftel A, Krueger B. Intraurethral alprostsdil (MUSE) for treatment of erectile dysfunction in spinal cord injured patients. J Spinal Cord Med 1998; 21: 186-187.

21 Bodner DR et al. Intraurethral alprostadil for treatment of erectile dysfunction in patients with spinal cord injury. Urology 1999; 53: 199-202.

22 Waldbaum $\mathbf{J}$ et al. Use of transurethral alprostadil to treat erectile dysfunction in spinal cord injured patients. Arch Phys Med Rehabil 1998; 79: 1184.

23 Costa $\mathrm{P}$ et al. Moxisylyte plasma kinetics in humans after intracavernous administration. Biopharm Drug Dispos 1992; 13: 671-679.

24 Costa $\mathrm{P}$ et al. Is the volume injected a parameter likely to influence the erectile response observed after intracavernous administration of an alpha-blocking agent? Eur Urol 1993; 24: 43-47. 
25 Hirsch IH et al. Use of intracavernous injection of prostaglandin E1 for neuropathic erectile dysfunction. Paraplegia 1994; 32: 661-664.

26 Tang SF, Chu NK, Wong MK. Intracavernous injection of prostaglandin E1 in spinal cord injured patients with erectile dysfunction. A preliminary report. Paraplegia 1995; 33: $731-733$.

27 Earle $\mathrm{CM}$ et al. The role of intracavernosal vasoactive agents to overcome impotence due to spinal cord injury. Paraplegia 1992; 30: 273-276.

28 Zaslau $\mathrm{S}$ et al. A simplified pharmacologic erection program for patients with spinal cord injury. J Spinal Cord Med 1999; 22: 303-307.

29 Sidi AA et al. Vasoactive intracavernous pharmacotherapy for the treatment of erectile impotence in men with spinal cord injury. J Urol 1987; 138: 539-542.

$30 \mathrm{Kapoor}$ VK et al. Intracavernous papaverine for impotence in spinal cord injured patients. Paraplegia 1993; 31: 675-677.

31 Beretta $\mathrm{G}$ et al. Intracavernous injection of papaverine in paraplegic males. Acta Eur Fertil 1986; 17: 283-284.

32 Renganathan R, Suranjan B, Kurien T. Comparison of transdermal nitroglycerin and intracavernous injection of papaverine in the treatment of erectile dysfunction in patients with spinal cord lesions. Spinal Cord 1997; 35: 99-103.

33 Chancellor MB et al. Prospective comparison of topical minoxidil to vacuum constriction device and intracorporeal papaverine injection in treatment of erectile dysfunction due to spinal cord injury. Urology 1994; 43: 365-369.

34 Zasler ND, Katz PG. Synergist erection system in the management of impotence secondary to spinal cord injury. Arch Phys Med Rehabil 1989; 70: 712-716.

35 Heller L et al. An open trial of vacuum penile tumescence: constriction therapy for neurological impotence. Paraplegia 1992; 30: 550-553.

36 Clontz D et al. Effects of sildenafil on spinal cord injury patients suffering from erectile dysfunction. J Spinal Cord Med 1999; 22: 48-49.

37 Anonymous. Sildenafil in men with spinal cord injury. Nurses Drug Alert 1999; 23: 12.

38 Derry FA et al. Efficacy and safety of oral sildenafil (Viagra) in men with erectile dysfunction caused by spinal cord injury. Neurology 1998; 51: 1629-1633.

39 Shenot PJ, Rajan R, Rivas DA. Initial experience with sildenafil (viagra) in spinal cord injured men with erectile dysfunction. J Spinal Cord Med 1999; 22: 49.

40 Giuliano $\mathrm{F}$ et al. Randomized trial of sildenafil for the treatment of erectile dysfunction in spinal cord injury. Sildenafil Study Group. Ann Neurol 1999; 46: 15-21.

41 Maytom MC et al. A two-part pilot study of sildenafil (VIAGRA) in men with erectile dysfunction caused by spinal cord injury. Spinal Cord 1999; 37: 110-116.

42 Giuliano $\mathrm{F}$ et al. Sildenafil citrate (VIAGRA): a novel oral treatment for erectile dysfunction caused by traumatic spinal cord injury. Int J Clin Pract 1999; 102(Suppl): 24-26.

43 Hultling C. Partners' perceptions of the efficacy of sildenafil citrate (VIAGRA) in the treatment of erectile dysfunction. Int J Clin Pract 1999; 102(Suppl): 16-18.

44 Hultling $\mathrm{C}$ et al. Quality of life in patients with spinal cord injury receiving Viagra (sildenafil citrate) for the treatment of erectile dysfunction. Spinal Cord 2000; 38: 363-370.

45 Gans WH et al. Efficacy and safety of oral sildenafil in men with erectile dysfunction and spinal cord injury. $J$ Spinal Cord Med 2001; 24: 35-40.

46 Kier AJ et al. Sildenafil effects on spinal cord patients with erectile dysfunction. 16th American Association of Spinal Cord Injury Nurses Conference, 1999 pp 32-33.

47 Takeda H, Otani T, Ito Y. Efficacy of sildenafil citrate for ED associated with spinal cord injury. Int $J$ Impot Res 2000; 12(Suppl 2): s19.

48 Schmid DM, Schurch B, Hauri D. Sildenafil in the treatment of sexual dysfunction in spinal cord-injured male patients. Eur Urol 2000; 38: 184-193.

49 Raviv $\mathrm{G}$ et al. Sexual rehabilitation: clinical experience with sildenafil citrate (Viagra) in spinal cord injured patients. Int J Impot Res 2000; 12(Suppl 5): s1.

50 Laschke $\mathrm{S}$ et al. Efficacy and reproducibility of sildenafil (Viagra) in erectile dysfunction in spinal cord injured men. J Spinal Cord Med 2002; 25(Suppl 1): s43.

51 Sanchez RA et al. Efficacy, safety and predictive factors of therapeutic success with sildenafil for erectile dysfunction in patients with different spinal cord injuries. Spinal Cord 2001; 39: 637-643.

52 Golji H. Experience with penile prosthesis in spinal cord injury patients. J Urol 1979; 121: 288-289.

53 Green BG, Sloan SL. Penile prostheses in spinal cord injured patients: combined psychosexual counselling and surgical regimen. Paraplegia 1986; 24: 167-172.

54 Gross AJ et al. Penile prostheses in paraplegic men. $\mathrm{Br} J$ Urol 1996; 78: 262-264.

55 Iwatsubo E et al. Non-inflatable penile prosthesis for the management of urinary incontinence and sexual disability of patients with spinal cord injury. Paraplegia 1986; 24: 307-310.

56 Montague DK. Penile prosthesis implantation in men with neurogenic impotence. Sex Disabil 1994; 12: 94-98.

57 van der Aa HE et al. Sacral anterior root stimulation for bladder control in patients with a complete lesion of the spinal cord. Acta Neurochir (Wien) 1995; 134: 88-92.

58 van der Aa HE et al. Sacral anterior root stimulation for bladder control: clinical results. Arch Physiol Biochem 1999; 107: 248-256.

59 Moher D, Schulz KF, Altman DG. The CONSORT statement: revised recommendations for improving the quality of reports of parallel-group randomized trials. Ann Intern Med 2001; 134: 657-662.

60 Ioannidis JP et al. Better reporting of harms in randomized trials: an extension of the CONSORT statement. Ann Intern Med 2004; 141: 781-788. 